\title{
Veterinary parasitology teaching: Ten years of experience with the Vetsuisse curriculum
}

\author{
Schnyder, Manuela ; Hertzberg, Hubertus ; Mathis, Alexander ; Schönmann, Marietta ; Hehl, Adrian B
} ; Deplazes, Peter

\begin{abstract}
Pursuant to the Joint Declaration by 29 European education ministers in June 1999 in the city of Bologna, Italy, the so-called 'Bologna Process' was officially introduced at the Vetsuisse Faculty (Universities of Zurich and Berne) in Switzerland in 2007. The long-term goal of restructuring the study programmes was to create a common European Higher Education Area (EHEA), with uniform and clearly defined standards for degrees ("diplomas"). Accordingly, the Vetsuisse curriculum was organised as a 3-year Bachelor and a 2-year Master study program. For the final Federal examination in veterinary medicine, both programs and a master thesis have to be completed. Parasitology, as a subject, is introduced with selected examples in the ecology course during the first academic year. The second and third years of the Bachelor program comprise non-organ-centred (NOC) and integrated organcentred (OC) course modules, respectively. In the NOC modules, parasitology is taught in consecutive courses, focussing on topics including occurrence, biology, pathogenesis, clinical manifestations, diagnostics and the strategic principles of therapeutic and prophylactic interventions against major veterinary and zoonotic parasites. This syllabus is complemented with live demonstrations as well as practical laboratory exercises. Lecture notes, with defined learning objectives, are based on the textbook "Parasitology in Veterinary Medicine" which is available free of charge to students as an on-line edition in German. Furthermore, students review relevant parasitoses in the diagnostic context of OC case presentations. In another module, immunological aspects of parasitic diseases are elaborated on group sessions, supported through the use of specialist literature. The two-year Master program is divided into a core syllabus for all students, and elective subjects are chosen from six areas of specialisation (three each with clinical or non-clinical focus). Within the clinically focused specialisations, interactive teaching of control strategies against parasitoses of companion and farm animals is the focus. Students specialising in 'Pathobiology' experience a deep immersion in parasitology. Learning objectives are verified in different test formats. E-learning tools, including a learning management on-line platform, allow interactive student training in coproscopic diagnostic techniques and in arachno-entomology and provide case-oriented teaching. Since an aptitude test limits the number of first-year students in veterinary medicine in Switzerland (80 in Zürich, 70 in Berne), the conditions for students and teachers are similar each year. The fragmentation of teaching in veterinary parasitology, the reduction of the number of diagnostic exercises and clinically oriented day-1-skills pertaining to the control of parasitoses are critically commented upon.
\end{abstract}

DOI: https://doi.org/10.1016/j.vetpar.2018.01.033 


\section{(C) $\odot \otimes \Theta$}

The following work is licensed under a Creative Commons: Attribution-NonCommercial-NoDerivatives 4.0 International (CC BY-NC-ND 4.0) License.

Originally published at:

Schnyder, Manuela; Hertzberg, Hubertus; Mathis, Alexander; Schönmann, Marietta; Hehl, Adrian B; Deplazes, Peter (2018). Veterinary parasitology teaching: Ten years of experience with the Vetsuisse curriculum. Veterinary Parasitology, 252:148-152.

DOI: https://doi.org/10.1016/j.vetpar.2018.01.033 


\section{Veterinary parasitology teaching: ten years of experience with the}

\section{Vetsuisse curriculum}

3

4 Manuela Schnyder $^{a^{a}}$, Hubertus Hertzberg ${ }^{a}$, Alexander Mathis ${ }^{a}$, Marietta Schönmann ${ }^{b}$, Adrian Hehl $^{a}$,

$5 \quad$ Peter Deplazes ${ }^{a}$

6

$7 \quad{ }^{a}$ Institute of Parasitology, Vetsuisse Faculty, University of Zurich, Winterthurerstrasse 266a, 8057

$8 \quad$ Zürich, Switzerland

$9{ }^{\mathrm{b}}$ Dean's Office, Study Administration, Vetsuisse Faculty, University of Zurich, Winterthurerstrasse

$10 \quad 260,8057$ Zürich, Switzerland

11

12

13

14

15 *Corresponding author. Institute of Parasitology, University of Zurich, Vetsuisse Faculty,

16 Winterthurerstrasse 266a, 8057 Zürich, Switzerland.

17 Tel: +41 (0)44 63585 25; Fax: +41 (0)44 63589 07. E-mail: manuela.schnyder@uzh.ch 18

19 
ABSTRACT

Pursuant to the Joint Declaration by 29 European education ministers in June 1999 in the city of Bologna, Italy, the so-called 'Bologna Process' was officially introduced at the Vetsuisse Faculty (Universities of Zurich and Berne) in Switzerland in 2007. The long-term goal of restructuring the study programmes was to create a common European Higher Education Area (EHEA), with uniform and clearly defined standards for degrees ("diplomas"). Accordingly, the Vetsuisse curriculum was organised as a 3-year Bachelor and a 2-year Master study program. For the final Federal examination in veterinary medicine, both programs and a master thesis have to be completed. Parasitology, as a subject, is introduced with selected examples in the ecology course during the first academic year. The second and third years of the Bachelor program comprise non-organ-centred (NOC) and integrated organ-centred $(\mathrm{OC})$ course modules, respectively. In the NOC modules, parasitology is taught in consecutive courses, focussing on topics including occurrence, biology, pathogenesis, clinical manifestations, diagnostics and the strategic principles of therapeutic and prophylactic interventions against major veterinary and zoonotic parasites. This syllabus is complemented with live demonstrations as well as practical laboratory exercises. Lecture notes, with defined learning objectives, are based on the textbook "Parasitology in Veterinary Medicine" which is available free of charge to students as an on-line edition in German. Furthermore, students review relevant parasitoses in the diagnostic context of OC case presentations. In another module, immunological aspects of parasitic diseases are elaborated on group sessions, supported through the use of specialist literature. The two-year Master program is divided into a core syllabus for all students, and elective subjects are chosen from six areas of specialisation (three each with clinical or non-clinical focus). Within the clinically focused specialisations, interactive teaching of control strategies against parasitoses of companion and farm animals is the focus. Students specialising in 'Pathobiology' experience a deep immersion in parasitology. Learning objectives are verified in different test formats. E-learning tools, including a learning management on-line platform, allow interactive student training in coproscopic diagnostic techniques and in arachno-entomology and provide case-oriented teaching. Since an aptitude test limits the number of first-year students in veterinary medicine in Switzerland (80 in Zürich, 70 in Berne), the conditions for students and teachers are similar each year. The fragmentation of teaching in veterinary parasitology, the reduction of the number of diagnostic 
49 exercises and clinically oriented day-1-skills pertaining to the control of parasitoses are critically

50 commented upon.

51

52 Keywords: Veterinary parasitology, teaching, Vetsuisse, Switzerland

53

54 


\section{Introduction}

Effective teaching of the subject "Veterinary Parasitology" has been under discussion in regular intervals within and beyond the framework of the WAAVP. Based on new evidence in the field of parasitology and also in didactics for higher education, continuous adaptations have been made. In particular, a trend away from the classical 'disciplinary approach', as applied by awarded veterinary parasitologists (Euzeby, 1996; Soulsby, 1994), towards a more problem-based, interdisciplinary approach has been implemented in several countries worldwide, in Europe (Gottstein and Eckert, 2002; Kramer and Genchi, 2002; Vercruysse and Eckert, 2002), Australia (Thompson et al., 2002) and North America (Stromberg, 2002). Concurrently, as a result of the $18^{\text {th }}$ International congress in Stresa, Italy, the WAAVP adopted a resolution in which minimum requirements in undergraduate teaching of veterinary parasitology were defined (Krecek, 2002). Among these, a fundamental principle concerning the minimal number of contact hours was restated, based on teaching expertise (Eckert, 2000) and on previously performed studies on the worldwide average hours employed for teaching veterinary parasitology (Cordero-del-Campillo et al., 1986). A total of at least $70-90$ contact hours, including lectures and practicals, were promoted. Interestingly, it was also stated that in addition to teaching basic skills, at least another 10-20 hours of problem-based and interdisciplinary activities could be applied in advanced teaching of veterinary parasitology. The focus of this advanced teaching might be placed on animal species or organ systems. In this resolution, the advantage of focussing on animal species rather than on organ systems emerged as a consensus, based on the spectrum of professional activities of veterinarians (Krecek, 2002).

The WAAVP resolution was evidently intended to support appropriate undergraduate education in veterinary science and to counteract a general trend to reduce contact hours, in favour of the above mentioned interdisciplinary and problem-based activities. Therefore, the proposal was directed at veterinary faculties and the authorities which were in charge of reforming the curricula (Krecek, 2002). In addition, common minimal standards were promoted in view of the increased flexibility of students. For example, the European student exchange program 'Erasmus' was started in 1987 with the aim of increasing student mobility and collaborations between the European Universities. The University of Zurich joined this program in 1992. 
In 1999, a Joint Declaration by 29 European education ministers in the city of Bologna, Italy, was made, which was the basis for the so called 'Bologna Process'. The long-term goal of this action was to restructure study programmes, in order to create a common European Higher Education Area with uniform and clearly defined standards for degrees (or "diplomas").

In Switzerland, a new curriculum, which was based on a more organ-focused and problem-based approach, was implemented in 1999 at the Faculty of Veterinary Medicine of the University of Berne. First experiences with this curriculum revealed some issues, particularly in disciplines associated with infectious diseases. Additional challenges, such as an increase of the necessary resources, i.e. study rooms, teaching personnel and finances were identified (Gottstein and Eckert, 2002). However, these experiences turned out to be valuable for the implementation of the following steps in the country.

In 2003, a common unified Vetsuisse curriculum for the two University sites for veterinary medicine, Berne and Zurich, was introduced (Lutz and Schläppi, 2008). The degree program still comprised 5 study years and was structured into modules, in order to be compatible with the 'Bologna Process', which was officially introduced at the Vetsuisse Faculty in 2007.

In the following, we will summarise our 10-year experience in teaching veterinary parasitology within the Vetsuisse curriculum based on the combination of a disciplinary as well as problem-based and organ-focussed approaches, discussing the advantages, disadvantages and challenges of such fragmentation.

\section{Veterinary Parasitology in the Vetsuisse curriculum}

The Vetsuisse curriculum is organised according to the 'Bologna Process' as a 3-year Bachelor and a 2-year Master study program. Thus, the study program actually includes 5 academic years, and in each of them 60 ECTS (European Credit Transfer System) points have to be acquired. As a guide value, one ECTS point corresponds to approximately 30 working hours for the students.

Admission conditions for the final Federal examination in Veterinary Medicine in Switzerland (comprising practical examinations in the subjects small animals, horses, farm animals and pathology) include the completion of both Bachelor and Master programs, two externships and a Master thesis. For details, see the English study guide for Veterinary Medicine at the University of Zurich, available online (www.vet.uzh.ch/en/Studium/vetmed.html). 


\subsection{Bachelor program}

117 Basics in parasitology are introduced, with important examples of animal parasitoses and zoonoses, in the first academic year in lectures (8 hours) (Table 1). Selected life cycles of protozoa, helminths and arthropods are presented, along with aspects of the basic biology of the parasites. Furthermore, the ecology of wild animal hosts or the husbandry conditions of domestic animal hosts are presented in the context of their veterinary or public health importance. The second and third years of the Bachelor program comprise courses in non-organ-centred (NOC) and integrated organ-centred (OC) modules. The NOC modules deal with biological and clinical as well as pathobiological aspects and closely correspond to what is defined as the 'disciplinary approach'. Parasitology is taught in consecutive course modules, focussing on topics such as life cycles, epidemiology, pathogenesis, clinical manifestations, immunology, diagnostics and the strategic principles of prophylactic and therapeutic interventions directed against major veterinary and zoonotic parasites. This syllabus is complemented with live demonstrations as well as practical laboratory exercises which are centred on microscopic and macroscopic examinations. Comprehensive lecture notes with defined learning objectives are based on the textbook 'Parasitology in Veterinary Medicine' (Deplazes et al., 2016), of which the German edition (Deplazes et al., 2013) is available for students on-line and free of charge. This module is taught in a multifunctional room with up to 84 fully equipped working places (microscope, binocular). At the end of the NOC modules, an individual oral examination is held, preceded by a preparation period of 20 minutes to examine two parasite samples (microscopy slides, organs, isolated parasites) and read two theoretical questions, followed by 20 minutes for a discussion about the parasite samples and the questions. The exam is conducted by two parasitologists, in the presence of an independent veterinarian and additionally recorded through a written protocol. A 'pass' grade is required for a student to enter the Master program (years 4 and 5). In addition, students get the opportunity to review relevant parasitological diseases within OC course modules, in the context of the organ-centred topics blood/immune system, digestion/metabolism, heart/circulation/respiration, and skin/thermoregulation. The focus in these interactively taught practical modules is clearly on diagnosis, actively trained by the students on the basis of authentic case presentations. 
Learning objectives of the OC course contents are verified by individual online examinations that have been implemented and recently renewed with substantial administrative and financial effort. A professional platform (Q-Exam $\left.{ }^{\circledR}\right)$ assures compliance with formal quality criteria. The efforts necessary to generate appropriate question/answer combinations for regular alternative replacement questions should not be underestimated.

\subsection{Master program}

The two-year Master program is divided into a so-called core syllabus for all students and an elective subject chosen from six areas of specialisation: three with a clinical focus (companion animals including zoo animals, horses, and farm animals) and three with paraclinical foci (pathobiology, biomedical research, veterinary public health). The fifth and last study years mainly consist of rotations in the various clinics and in pathology, and of two externships.

Within the clinically focused specialisations, interactive teaching of diagnostic strategies, prophylactic and therapeutic measures against the most important parasitic diseases of companion and farm animals and horses are the major teaching activities in veterinary parasitology. Particular emphasis is given to strategies for the control and treatment of parasitic diseases on an individual or herd level. Students are evaluated by means of group case simulations and presentations. The clinically relevant subjects of veterinary parasitology mentioned above are deepened separately within each of the clinically focussed specialisations. This precludes that all students acquire the same broad and practically-oriented parasitological knowledge for the most relevant animals.

Students wishing to specialise in 'Pathobiology' experience a particularly deep immersion in parasitology, other infectious disease topics (virology, bacteriology), pathology and immunology during practical courses with two foci: 1) to obtain day-1-skills for practising first-line laboratory methods; 2) to gain a profound knowledge of diagnostic methods, including test establishment and evaluations. Learning objectives are verified through evaluations of individual participation and practical skills as well as presentations in a general laboratory class, and by means of individual oral and written reports of an independently chosen and performed project. 
172 Within this specialisation, the students get the opportunity to choose a topic for a Master thesis 173 proposed by pathobiology research groups, but they are also encouraged and supported to develop 174 their own projects.

175 All students follow the module 'immuno-infectiology', shared with virology, bacteriology and 176 immunology. Immunological aspects of parasitic infections or infestations are reinforced in groups of 177 5-6 students. General aspects, such as immunomodulation, immunoprotection, the hygiene 178 hypothesis and the challenges of vaccine development as well as immunodiagnostics, are deepened using selected literature. Poster presentations by the students and the preparation of abstracts ensure that all students benefit from the work done by each group. Learning objectives are evaluated by presentations (individually and as part of a group) and group audits. In this module 'immuno-infectiology', there is some repetition, and the module contributes to the fragmentation of the subject veterinary parasitology. On the other hand, this different learning environment approach strongly promotes interactivity within groups and also with lecturers, thereby fulfilling also the need for training social competence and presentation techniques. Furthermore, by reading specialist literature and by giving the opportunity to critically discuss scientific contents, the module prepares the students for the Master thesis.

\subsection{Master thesis}

190

Single lectures, covering topics such as literature search and expertise for scientific work and basics in image processing, are part of the core curriculum. In addition, elective IT and language courses (including 'scientific writing') and others are offered by the University. With few exceptions, the Master thesis represents the first interface with scientific writing. Master theses with a parasitological topic specialisation. In the first case, students are trained to carry out the most important parasitological diagnostic methods during the two week Pathobiology course in the $8^{\text {th }}$ semester (Table 1). The master theses can be mostly performed within the pathobiology specialisation. Students of the clinical specialisations, instead, are fully involved in the clinical education and are expected to work for the master thesis beside this ambitious program, a situation that needs to be improved in the future. 
Since an aptitude test limits the number of first-year students of veterinary medicine in Switzerland (80 in Zürich, 70 in Berne), the capacity requirements for teaching are similar each year. As our room for practical lessons has a capacity of more than 80 students, no repetition of any course or group splitting is needed, and, therefore, no additional teaching resource is usually required. Occasionally, the 2-week course for Pathobiology students in the $8^{\text {th }}$ semester (see Table 1 ) has to be repeated, because a part of this course is compulsory also for Master students focussed in clinical subjects. This has, however, the advantage of a common basic instruction and introduction into the daily business of the Institute for all Master students. Within this and other elective courses, the size of the classes allows a close interaction between teachers and students.

\section{E-learning environment}

The University of Zurich uses OLAT (Online Learning and Training) as a strategic learning management on-line platform. OLAT works as a document repository and can be used as communication platform, linking teachers and students in asynchronous (forum) and, occasionally, synchronous (chat) ways. It also contributes to ameliorate and supervise self-learning processes (Lutz and Schläppi, 2008). OLAT has been developed by the University of Zurich and is continuously being refined. Students and staff of the University of Zurich obtain access through their personal digital access data that also allow access to WLAN at the University and worldwide access to their webmail and other learning courses.

With the term 'E-learning', we generally refer to educational technology being "the study and ethical practice of facilitating learning and improving performance by creating, using, and managing appropriate technological processes and resources" (Robinson et al., 2016). Computer-based tools allow independent training during or outside of contact hours, and online-based exercises can be applied for interactive exchanges and also for examinations. Such tools are promoted to improve learning outcomes, and students should be trained in their self-guided acquisition of knowledge. Highest priority is given to interactivity, meaning that exchanges between students, teachers and the learning material are thought to increase knowledge and competencies. In particular, active 
232

233

234

235

236

237

238

239

240

241

242

243

244

245

246

247

248

250

251

252

253

254

255

256

257

258

259

260

261

participation is considered more sustainable for the acquisition of knowledge than listening or reading alone. In addition, this helps to anchor expertise and practical knowledge more firmly. Innovative learning forms are aimed at supporting and optimising learning processes, and have to be evaluated and adapted accordingly. Similarly, feedback from students is important to evaluate the success of the transmission of subject matter, while students actively deal with different learning procedures and have the possibility to reflect on their own learning processes.

E-learning tools in veterinary parasitology are promoted to improve learning processes of students but not necessarily to reduce the number of student contact hours. They can allow a more vivid and striking presentation of subject matter, as well as stimulating the learning experience in a different way than just by reading texts. An evident advantage is that the teaching material is available at any time (Huang et al., 2006), and is therefore compatible with the individual study program of the students. Another relevant factor is that electronic display of parasites helps preserve physically available teaching material, which is especially important in the case of rare specimens. Individual training sessions at the microscope or personal exchanges when discussing clinical cases are invaluable, but not always possible.

Our E-learning tools in parasitology allow interactive student training in coproscopic diagnostic techniques and in arachno-entomology. These tools are recommended as preparation for practical courses in the OC course modules and for revision of the practical parts of the NOC modules. Student evaluations of these E-learning tools were always positive in the last years. Disappointingly, the use of these tools during the semester is rather limited. Confronting the students with this discrepancy revealed that the students postpone the use of the tools to the exam preparation due to priorities in other subjects examined before veterinary parasitology. This is possibly a consequence of the 'Bologna Process' in which each module needs to be terminated by an examination, causing the time attributed to self-study (including the use of such training tools) used for preparation of other upcoming exams instead.

The CASUS $®$ platform (http://www.instruct.eu/de/start) completes the array of on-line training tools and is designed to provide case-oriented teaching for students and specialists. It is an interactive multimedia learning system that allows training based on case reports, therefore linking different aspects of veterinary parasitology and also broader features of veterinary medicine. 


\section{Consequences of the subdivision of the curriculum in a Bachelor and Master program}

263

264

265

266

267

268

269

270

271

272

273

274

275

276

277

278

279

280

281

282

283

284

285

286

287

288

289

290

291

As indicated, the structure of the NOC courses reflects a classical 'disciplinary' approach. It represents the basics and allows a systematic introduction to veterinary parasitology. This course is considered indispensable because it furnishes the students with a solid base for other approaches, such as the organ- and problem-based approaches and those focusing on animals (Eckert, 2000; Vercruysse and Eckert, 2002). Based on regularly performed surveys, the combination of lectures with practical exercises and demonstrations is highly appreciated by the students. We estimate that hands-on training and own visual observations are important components of interactivity that contribute to sustainable learning processes. For this, fortunately, veterinary parasitology is a particularly rewarding subject, to be presented with 'exciting and stimulating examples' (Soulsby, 1994). At the Vetsuisse Faculty, sustainability of learning contents is supported by the textbook Parasitology for Veterinary Medicine (German version available also online free of charge) and a concise course script. Passing the oral and practical exams at the end of the fifth semester is compulsory for starting the Master program. Thus, the great effort of a 40 min individual examination, in which 3 highly qualified persons and a teaching assistant are involved, is justified.

After the uniform Bachelor program for all students, the Master program offers the opportunity to acquire a larger number of skills within one of the 6 elective focus curricula. A common core syllabus for all students should, nevertheless, guarantee an adequate start of a professional career in any direction. However, past experience shows that the step from the Bachelor to the Master program represents a challenge for both students and lecturers. For some students, selection of the focus subject has to consider different factors, based on individual preferences and/or future opportunities. For the lecturers, it is desirable to have an adequate number of students, in order to work with suitable group sizes that correlate with the available resources (training personnel, rooms and laboratory equipment).

\section{Selection of students for a career in veterinary parasitology}

Importantly, recruiting students who focus on Pathobiology should result in appropriate candidates for continuing education in veterinary parasitology. Although Master theses performed by students with a 
292

293

294

295

296

297

298

299

300

301

302

303

304

305

306

307

308

309

310

311

312

313

314

315

316

317

318

319

320

321

clinical focus can represent an ideal combination of the student's interests and their preferred access to patients and patient material for parasite issues, there is the potential to develop topics with more scientific profundity. In such cases, the Master thesis can constitute a suitable starting point for a doctoral thesis. Currently, at the Vetsuisse Faculty, the doctoral thesis (title: Dr. med. vet.) is still a first step towards a specialisation for veterinary graduates, as a directly accessible $\mathrm{PhD}$ program has not yet been implemented. At present, the veterinary students can enrol in the Life Science Zurich Graduate School of the University of Zurich or participate in the Graduate School for Cellular and Biomedical Sciences of the University of Berne, with some difficulty: as the Master of the Vetsuisse Faculty is not recognised as equivalent to a Master of the Faculties of Science, the acquisition of further ECTS and additional exams are required.

Additionally, since 2003, among the specialisations within the European Board of Veterinary Specialists (EBVS), European veterinary parasitologists are offered the opportunity to obtain the specialisation through a residency program of the European Veterinary Parasitology College (EVPC). The program has been fully recognised since 2013. Therefore, a challenge identified more than 15 years ago has been mastered (Eckert, 2000). Within this veterinary specialisation, the residents deal with wide-ranging topics in the field, representing, among others, access to valuable teaching resources.

\section{Concluding remarks}

The fragmentation of teaching in veterinary parasitology, connected with the reduction of diagnostic exercises, partially precludes newly graduated students from being sufficiently prepared to cope with the requirements in clinical practice. Such concerns with regard to day-1-skills have been raised generally. Based on complaints from practitioners, lecturers and students concerning the graduate outcome from veterinary studies, the Vetsuisse Faculty decided to extend the curriculum by two additional semesters. One of the major boosts for the extension is to provide an adequate time interval to conduct the Master thesis.

Specialisation in veterinary medicine conforms more and more to the situation in human medicine, including the trend for specialised practitioners. Still, priority must be given to teach veterinary parasitology by supporting students to gain practicals skills for research and diagnostics as a sound 
322 basis for all specialisations in the curriculum and for the future academic, continuing education as 323 well. Organisations such as the European Scientific Counsel for Companion Animal Parasites 324 (ESCCAP) or the Companion Animal Parasite Council (CAPC) provide helpful support, contributing to 325 the dissemination of robust and sound knowledge. For farm animals, optional continuous education in 326 applied veterinary parasitology is provided by specialist organisations and federal institutions, 327 supporting the implementation of regulations, including the correct usage of drugs.

328 Recruiting appropriate candidates for a career in veterinary parasitology was (Eckert, 2000) and still is 329 challenging. The aim should be to "close the circle": appropriately instructed young graduates should 330 be motivated to become specialised veterinary parasitologists (e.g., diplomates of the EVPC) and 331 'research professionals' who will be the teachers in the future, able to motivate new undergraduate 332 students to build a career in veterinary parasitology. 


\section{References}

Cordero-del-Campillo, M., Rojo-Vazquez, F.A., Diez-Banos, P., Castanon-Ordonez, L., PereiraBueno, J.M., Diez-Banos, N., Hidalgo-Arguello, R., 1986. Teaching veterinary parasitology throughout the world. Vet. Parasitol. 19, 1-12.

Deplazes, P., Eckert, J., Mathis, A., von Samson-Himmelstjerna, G., Zahner, H., 2016. Parasitology in Veterinary Medicine. Wageningen Academic Publishers, Wageningen.

Deplazes, P., Eckert, J., von Samson-Himmelstjerna, G., Zahner, H., 2013. Lehrbuch der Parasitologie für die Tiermedizin. Enke Verlag, Stuttgart.

Eckert, J., 2000. WAAVP/Pfizer award for excellence in teaching veterinary parasitology: Teaching of veterinary parasitology - quo vadis? Vet. Parasitol. 88, 117-125.

Euzeby, J., 1996. WAAVP/Pfizer award for excellence in teaching veterinary parasitology: My philosophy on teaching parasitology and parasitic diseases. Vet. Parasitol. 64, 21-29.

Gottstein, B., Eckert, J., 2002. Various approaches of teaching veterinary parasitology. Vet. Parasitol. $108,267-272$.

Huang, W.Y., Wang, M., Suo, X., Lun, Z.R., Zhu, X.Q., 2006. How is veterinary parasitology taught in China? Trends Parasitol. 22, 564-567.

Kramer, L., Genchi, C., 2002. Teaching of veterinary parasitology: the Italian perspective. Vet. Parasitol. 108, 317-322.

Krecek, R., 2002. Resolution on teaching veterinary parasitology. World Association for the Advancement of Veterinary Parasitology (WAAVP). Vet. Parasitol. 108, 333-335.

Lutz, T.A., Schläppi, S., 2008. Das Vetsuisse-Curriculum und die Umgestaltung der Studiengänge nach "Bologna". Schweiz. Arch. Tierheilk. 150, 324-326.

Robinson, R., Molenda, M., Rezabek, L., 2016. Facilitating learning. Association for Educational Communications and Technology (www.aect.org/publications/EducationalTechnology/ER5861X_C002.pdf.)

Soulsby, L., 1994. WAAVP and Pfizer Award for excellence in teaching veterinary parasitology. Vet. Parasitol. 54, 23-26.

Stromberg, B.E., 2002. Teaching veterinary parasitology: the North American perspective. Vet. Parasitol. 108, 327-331. 
364 Thompson, R.C., Lymbery, A.J., Hobbs, R.P., 2002. Teaching of parasitology to students of veterinary 365 medicine and biomedical sciences. Vet. Parasitol. 108, 283-290.

366 Vercruysse, J., Eckert, J., 2002. Teaching of undergraduate veterinary parasitology in some 367 European countries. Vet. Parasitol. 108, 309-315.

368

369 
Table 1: Schematic representation of veterinary parasitology teaching within the Vetsuisse curriculum.

\begin{tabular}{|c|c|c|c|}
\hline \multicolumn{4}{|c|}{ Bachelor program } \\
\hline Semester & Topic & $\begin{array}{l}\text { No. of hours (h), type } \\
\text { of lesson }\end{array}$ & Type of examination \\
\hline Semester 2 & basic parasitology and ecology & $8 \mathrm{~h}$, lecture & written, MC \\
\hline Semester 3 & $\begin{array}{l}\text { OC, module haematology and } \\
\text { immune system organs }\end{array}$ & $2 \mathrm{~h}$, practical & $\begin{array}{l}\text { written, MC within the } \\
\text { module }\end{array}$ \\
\hline Semester 4 & NOC, helminthology & $\begin{array}{l}30 \mathrm{~h}, \quad \text { lectures } \\
\text { combined with practical } \\
\text { exercises }\end{array}$ & $\begin{array}{l}\text { oral and practical (end } \\
\text { of semester } 5 \text { ) }\end{array}$ \\
\hline & OC, module gastro-intestinal tract & $6 \mathrm{~h}$, practical & $\begin{array}{l}\text { written, MC within the } \\
\text { module }\end{array}$ \\
\hline Semester 5 & $\begin{array}{l}\text { NOC, arachno-entomology and } \\
\text { protozoology }\end{array}$ & $\begin{array}{l}28(30) h, \text { lectures } \\
\text { combined with practical } \\
\text { exercises }\end{array}$ & oral and practical \\
\hline & $\begin{array}{l}\text { OC, cardiovascular and } \\
\text { respiratory module }\end{array}$ & $2 \mathrm{~h}$, practical & $\begin{array}{l}\text { written, MC within the } \\
\text { module }\end{array}$ \\
\hline Semester 6 & OC skin and thermoregulation & $2 \mathrm{~h}$, practical & $\begin{array}{l}\text { written, MC within the } \\
\text { module }\end{array}$ \\
\hline \multicolumn{4}{|c|}{ Master program } \\
\hline Semester 7 & immuno-infectiology, parasitology & $10(12) \mathrm{h}$ & audit opinion \\
\hline Semester 8 & focus pathobiology, parasitology* & 2 weeks, practical & oral and written report \\
\hline & $\begin{array}{l}\text { focus in "small animals", "farm } \\
\text { animals", "horses", parasitology* }\end{array}$ & 2-6 h each, practical & group presentation \\
\hline Semester 9 & focus pathobiology, parasitology* & 3 months & written report \\
\hline
\end{tabular}

371

372 OC: organ-centred; NOC: non-organ-centred; MC: multiple choice; *: elective subjects chosen from

373 six areas of specialisation 